\title{
IMMUNOHISTOCHEMICAL EXPRESSION OF CATHEPSIN K IN EPIDERMAL TUMORS.
}

\author{
Mohamed Ibrahim Metwalli*, Afaf Helmy Ghanem*, Kamal Ahmad El Kashishy**, Rania \\ Abdel Aziz Zaki* \\ Dermatology, Venereology \& Andrology*\& pathology** Departments Faculty of Medicine - \\ Zagazig University, Sharkia, Egypt.
}

Corresponding author:

Rania Abdel Aziz Zaki, raniaelakad620@gmail.com
Background Cathepsins are a class of proteases that can degrade components of the extracellular matrix. Their role in tumor progression and invasion is well documented. Cathepsin $\mathrm{K}$ is a member of this family with strong collagenolytic and elastolytic activity.

Objectives To assess and compare the expression of cathepsin k protease in benign (seborrheic keratosis SK), premalignant (actinic keratosis AK), locally malignant (basal cell carcinoma BCC) and invasive cutaneous tumors (squamous cell carcinoma SCC).

Patients and methods The study included 45 participants divided into five groups: one control group (9 normal skin specimens) and four case groups (9 patients with SK, 9 patients with AK, 9 patients with BCC and 9 patients with SCC). All skin biopsies were subjected to immunohistochemical stain of cathespin $\mathrm{K}$.

Results The epithelial and stromal scores of cathepsin K were significantly higher in all epidermal tumors compared to the control group. Cathepsin $\mathrm{K}$ expression was noticed in the benign and premalignant tumors; however it was significantly lower than the invasive ones.

Conclusion Cathepsin $\mathrm{K}$ has a significant role in epidermal tumor invasion and increased expression is correlated with more aggressive tumors. Cathepsin $\mathrm{K}$ inhibitors can be a promising line of treatment of cutaneous tumors.

Keywords: cathepsin K, skin, tumors.

\section{INTRODUCTION}

$\mathrm{M}$ etastasis is a multistep process which involves local invasion then dissemination of cancer cells to anatomically distant organ sites. Local invasiveness involves entry of cancer cells into the surrounding tumor-associated stroma and thereafter into the adjacent normal tissue parenchyma. In order to invade the stroma, carcinoma cells must breach the basement membrane and the components of the extracellular matrix ECM through secreted proteases ${ }^{[1]}$. Mammalian proteases are classified into five distinct enzymatic classes based on their catalytic mechanism: metallo, aspartic, cysteine, serine, and threonine proteases ${ }^{[2]}$.

Cathepsins are a class of proteases that were initially considered to be responsible only for intracellular peptide hydrolysis; however several cathepsins were found to have additional extracellular functions ${ }^{[3]}$. The cathepsin family includes (cathepsin A, B, C, $\mathrm{D}, \mathrm{E}, \mathrm{F}, \mathrm{G}, \mathrm{H}, \mathrm{L}, \mathrm{K}, \mathrm{O}, \mathrm{S}, \mathrm{V}, \mathrm{W}, \mathrm{X})$. Cathepsin B, C, F, H, L, K, O, S, V, W and X are cysteine proteases of the papain family, and represent the largest and best-known class of cathepsins. Cathepsin A and $\mathrm{G}$ are serine proteases, while cathepsin $\mathrm{D}$ and $\mathrm{E}$ are aspartic proteases ${ }^{[4]}$.

Cathepsins are highly expressed in various human cancers where they are secreted not only by the malignant cells, but also the stromal cells closely associated with the tumour. Their role in tumor progression is well documented. In addition to proteolysis, cathepsins also promote proliferation, motility and angiogenesis ${ }^{[5,6]}$. Cathepsin $\mathrm{K}$ is a cysteine protease that belongs to this family with strong proteolytic activity. It is mainly responsible for the degradation of bone matrix by osteoclasts and plays a key role in 
understood $^{[6]}$. The expression of cathepsin $\mathrm{K}$ has been studied in various epidermal tumors including melanoma, BCC and SCC ${ }^{[5-7]}$.

Seborrheic keratoses are the most common benign epidermal tumors in elderly. They are believed to be more prevalent among Caucasians and to affect roughly equal numbers of men and women. They usually present with sharply demarcated stuck on papules on the skin ${ }^{[8]}$. Meanwhile, actinic keratosis (AK) is the most common form of carcinoma in situ that occurs in the skin. It lies in the middle of a spectrum between early actinic damage and late invasive SCC. Only when $\mathrm{AK}$ penetrates the basement membrane and invades the dermis does it become squamous cell carcinoma ${ }^{[9]}$.

Basal cell carcinoma (BCC) is a locally invasive epithelial tumor with low malignant potential that arises from cells of the basal epidermis layer. It is the most common skin cancer as it accounts approximately $80 \%$ of non-melanoma skin cancer ${ }^{[10]}$. Squamous cell carcinoma (SCC) is the second most common type of skin cancer. The head and neck region is the most commonly affected sites comprising $67 \%$ of the cases. There are many factors that contribute to the aggressiveness, recurrence rate, and metastatic potential of SCC ${ }^{[11]}$. Invasive SCC up to $2 \mathrm{~mm}$ tumor thickness usually carries no risk of metastasis. Tumors between 2 and $6 \mathrm{~mm}$ have a risk of metastasis of about $4 \%$ and the risk increases to $18 \%$ with thickness larger than $6 \mathrm{~mm}^{[12]}$.

Few studies have investigated the role of cathepsin $\mathrm{K}$ in discrete skin tumors with inconsistent results. Therefore, we tried to confirm its integral part in the invasiveness of skin tumors through a larger scale study with comparison between its expression in benign, premalignant and malignant tumors.

\section{PATIENTS AND METHODS}

This case-control study was carried out at the Dermatology and the Pathology department, Faculty of Medicine, Zagazig University Hospitals in the period from January 2017 till September 2017. Thirty six patients (15 men and 2) women) aged $35-72$ years (a mean of $53.08 \pm 8.3$ ) with epidermal
$\mathrm{K}$ in tumors has been investigated but not yet fully

skin tumors were enrolled in the study. They were categorized into four case groups (A, B, $\mathrm{C}, \mathrm{D})$ each one included nine patients with a total of 36 patients. Group (A) included 9 patients with SK, group (B) included 9 patients with $\mathrm{AK}$, group $(\mathrm{C})$ included nine patients with BCC and group (D) included nine patients with SCC. The diagnosis of the skin tumor was established by clinical, dermoscopic and histopathologic examination. The control group included nine paraffinized blocks of normal skin removed from patients undergoing plastic surgery. The control group was age and sex matched to the case group. Dermoscopic examination was done using handheld dermatoscope with 10 fold magnification (3gen Dermlite, Schuco International (London) Itd). Dermoscopic images were taken and dermoscopic signs were reported for each tumor.

The study was performed with approval from The Institutional Review Board (IRB) at Zagazig University. All patients gave their written informed consent. Skin biopsy specimens (4mm punch biopsy in SK, AK or excisional biopsy in BCC, SCC) were obtained from each tumor. The specimens were fixed in $10 \%$ neutral buffered formalin and processed for paraffin embedding. Serial $4 \mu \mathrm{m}$ sections were obtained from paraffin blocks and stained with Haematoxylin and Eosin stain for routine histopathological diagnosis and immunohistochemical staining with Cathepsin K mouse monoclonal antibody (Santa Cruz Biotechnology; Santa Cruz, CA) which can detect cathepsin $\mathrm{K}$ of human origin with the following steps according to Hsu et al $^{[13]}$ :

Sections were deparaffinized with xylene and rehydrated through descending strengths of alcohol followed by antigen retrieval by autoclaving the slides with $10 \mathrm{mmol} / \mathrm{L}$ citrate buffer at $21{ }^{\circ} \mathrm{C}$ for 30 minutes in microwave oven at $\mathrm{PH}$ 6. To block endogenous peroxidase activity, slides were incubated in $2 \%$ hydrogen peroxide for 10 minutes followed by washing in PBS. Blocking for non-specific protein binding was done using 
normal goat serum and bovine serum albumin followed by washing in PBS.

2-3 drops of the primary monoclonal antibody was added on each case and control slide to cover it. The slides were incubated in humidity chamber all night at $2-8^{\circ} \mathrm{C}$ then rinsed with buffer solution. In addition, incubation with secondary antibody (biotinylated link antibody) was done for 30 min. at room temperature followed by washing in PBS. To apply the enzyme label, the slides were then incubated with peroxidase- labeled streptavidin for 15 minutes at room temperature. Diaminobenzidine (DAB) was added as a chromogen and counter staining was performed using Mayer's hematoxylin for 30 seconds.

The immunohistochemical expression of cathepsin $\mathrm{k}$ was assessed semi quantitatively by the percent of cells with positive staining in the cytoplasm as described in a previous study of Yan et al ${ }^{[6]}$. The positivity was assessed for both the epithelial and the stromal component and the percentage of positivity was recorded for each compartment. The score was as follows: Negative (0): if no cathepsin k positive cells. Weakly positive $(1+)$ : if $<25 \%$ positive cells. Moderately positive $(2+)$ : if $25-50 \%$ positive cells. Strongly positive $(3+)$ : if $>50 \%$ positive cells.

\section{STATISTICAL ANALYSIS}

It was performed using the Statistical Package for Social Sciences version 16.0 (SPSS for Windows 16.0, Inc., Chicago, IL, USA). Data were represented as mean, standard deviation, median, and range for quantitative data while frequency and percentage were used for qualitative data. Not normally distributed data were compared using Mann Whitney test (MW) and Kruscal Wallis tests. Statistical analysis of qualitative data was done using Chi- square test. For correlations Pearson and Spearman correlation coefficients were used. All P values were based on a 2-tailed distribution, and the corresponding $\mathrm{P}$ value: nonsignificant (NS) difference if $\mathrm{P}>0.05$, significant(S) difference if $\mathrm{P}<0.05$ and highly significant (HS) difference if $\mathrm{P}<$ 0.001 .

\section{RESULTS}

The demographic, clinical, and histopathological characteristics of the groups studied are presented in table 1 , dermoscopic findings are presented in table 2.

\section{Immunohistochemical results}

The expression of cathepsin $\mathrm{K}$ in normal skin was observed in the sebaceous glands, eccrine glands and the outer root sheath of the hair follicles that served as positive controls. In epidermal tumors, cathepsin $\mathrm{K}$ was expressed by both the epithelial and the stromal cells including fibroblasts and inflammatory cells, figures (1-4).

The epithelial scores of cathepsin $\mathrm{K}$ were significantly higher in all case groups compared with the normal control group ( $p$ $<0.001$ ) except in the group of SK that showed no statistical difference compared to control group. Moreover, the epithelial scores showed a statistically significant difference $(\mathrm{p}=0.001)$ within the four case groups with the mean score in SK (0.67), AK (0.89), BCC (2.00) and SCC (1.78). Regarding cathepsin $\mathrm{K}$ expression in peritumoral stroma, the stromal scores showed evident elevation in all the four groups compared with the normal control group ( $p<0.001)$. There was a statistically significant difference $(\mathrm{p}=0.001)$ within the four case groups regarding their stromal scores with the mean score in SK (1.22), AK (0.89), BCC (2.00) and SCC (2.11), table 3.

There was a high statistically significant difference $(p<0.001)$ between the mean epithelial score of the benign tumors group (SK, AK) (0.78) and the mean epithelial score of the invasive tumors group (BCC, SCC) (1.89). Furthermore, there was a statistically significant difference $(p=0.001)$ between the mean stromal score of the benign tumors group (SK, AK) (1.06) and the mean stromal score of the invasive tumors group (BCC, SCC) (2.06), table 4. Post-hoc analysis of the difference between AK and SCC revealed statistically significant difference regarding the epithelial score of cathepsin $\mathrm{K}(\mathrm{p}=0.02)$ and the stromal score $(\mathrm{p}=0.01)$. 
Both epithelial and stromal scores were significantly positively correlated in all the four case groups $(p<00.1)$ with a correlation coefficient $(\mathrm{r}=0.882)$, figure 5 . In the BCC group the correlation between the epithelial and the stromal score was highly statistically significant $(\mathrm{p}<00.1)$ with a correlation coefficient $(\mathrm{r}=0.925)$. A significant positive correlation was also found between the epithelial and the stromal scores of SCC ( $\mathrm{p}=$ $00.1)$ with a correlation coefficient $(r=0.867)$.

There was a positive correlation between the epithelial score and the tumor grade of SCC $(p=0.018)$. Meanwhile, there was a high statistically significant correlation between the epithelial and stromal scores with the tumor size in the four case groups while no correlation was found with the age of the patients. There was a statistically significant correlation between the epithelial sore $(\mathrm{p}=0.014)$ and the stromal score $(\mathrm{p}=0.022)$ with the finding of dermoscopic hemorrhage in the SCC group.

\section{DISCUSSION}

Tumor invasion is a three-step process involving changes in tumor cell adhesion, proteolytic degradation of the ECM and migration of tumor cells in a proteolytically modified ECM ${ }^{[14]}$. The first association between proteases and cancer was reported by Fischer ${ }^{[15]}$ who proposed that the proteolytic activity of cancer cells could be responsible for the degradation of ECM, thereby enhancing invasion of tumor cells into the surrounding tissue.

The peritumoral stroma has a significant influence on tumor cell function and behavior via cell contact, secreted factors and ECM modification ${ }^{[16]}$. Therefore, the tunor cells and stroma constitute together what is called tumor microenvironment TME ${ }^{[14]}$. In our study, both epithelial and stromal cells showed significant expression of cathepsin K. The expression of this proteolytic enzyme in stromal cells signifies the role of TME in the process of carcinogenesis and metastasis.

Cathepsin $\mathrm{K}$ expression was observed in the epithelial and stromal compartments of benign tumors (SK, AK), however they only showed weak positivity $(+1)$. The expression of cathepsin $\mathrm{K}$ in benign tumors can be explained by its role in the natural course of tumor growth and expansion through proteolysis. In addition, it has several functions other than proteolysis e.g. angiogenesis and apoptosis which are also required by normal tissue. Despite expression in benign tumors, Cathepsin $\mathrm{K}$ expression was statistically significantly lower in the benign group ( $\mathrm{SK}$ and $\mathrm{AK}$ ) compared to the invasive group (BCC and SCC) (p <0.001). Cathepsin $\mathrm{K}$ expression was significantly lower in $\mathrm{AK}$ compared to its counterpart invasive tumor SCC $(p=0.001)$. The difference in its expression between the SCC and its premalignant tumor $\mathrm{AK}$ demonstrates the role of this proteolytic enzyme in tumor invasion. Therefore, we can deduce that AK lesions with higher expression level of cathepsin $\mathrm{K}$ are more likely to progress into invasive SCC.

Our results contradicted with previous studies of Yan et al ${ }^{[6]}$ and Ishida et al ${ }^{[7]}$ who couldn't detect cathepsin $\mathrm{K}$ in their examined benign tumors ( $\mathrm{SK}$ and $\mathrm{AK}$ ). On the contrary, Quintanilla-diek et al ${ }^{[5]}$ who studied the expression profile of cath $\mathrm{K}$ in melanocytic lesions, found cathepsin $\mathrm{K}$ positivity in the majority of benign melanocytic nevi. They speculated that cathepsin $\mathrm{K}$ expression in benign nevus cells enables them to invade into the dermis, which is part of their natural "life cycle" unrelated to malignancy. They also hypothesized that the innate capability of melanocytes to invade, for example during embryonal migration from the neuroectoderm into the epidermis might be explained by cathepsin $\mathrm{K}$ expression. Similarly, Rao et al ${ }^{[17]}$ found prominent cathepsin $\mathrm{K}$ expression in $88 \%$ of his studied benign nevi.

In basal cell carcinoma, both the epithelial and the stromal scores were significantly statistically higher in the BCC group than the normal control group. As BCC is characterized by a prominent inflammatory reaction to limit the tumor spread, cathepsin $\mathrm{K}$ expression was prominent in the inflammatory cells surrounding the tumor nests, mainly observed at the front tumor borders. That was consistent with the study of Ishida et al ${ }^{[7]}$ who studied 50 BCC cases and reported strong cathepsin $\mathrm{K}$ expression $(+3)$ 
in $90 \%$ of cases and suggested that its expression in BCC may explain the mucinous stroma around the nests through mediating extracellular matrix degradation. These results contradicted with the earlier study of Quintanilla-diek et al ${ }^{[5]}$ who observed weak and focal positivity in their BCC cases. This could be attributed to the fewer number of studied cases (only three bcc cases).

As cathepsin $\mathrm{K}$ is normally expressed in the outer root sheath of the hair follicles, Ishida et al ${ }^{[7]}$ suggested that its expression in BCC seems to reflect the differentiation toward the outer root sheath of hair follicles which is considered the most possible origin of BCC. Expression of other types of the cathepsin family was also reported in BCCs lesions including cathepsins $\mathrm{B}, \mathrm{L}$, and $\mathrm{D}^{[18]}$.

No significant difference in cathepsin $\mathrm{K}$ expression was noticed between the BCC and the SCC groups (epithelial score $\mathrm{p}=0.5$, stromal score $p=0.9)$. Tsuboi et al ${ }^{[19]}$ who studied another proteolytic enzyme from the same family (cathepsin D) found high cathepsin D activity in SCC and BCC, but with no significant difference between the tumors. Based on these findings, he suggested that no difference exists in the lysosomal functions of the tumors.

The expression of cathepsin $\mathrm{K}$ was significantly higher in SCC than the normal control group regarding both the epithelial score $(p=0.001)$ and the stromal score $(p<0.001)$. Similar to BCC, the expression was noticed by both the tumor and stromal cells with the highest stromal score in the SCC group (mean=2.11). Quintanilla et al ${ }^{[5]}$ studied four SCC cases and found cathepsin K positivity only in the peritumoral stromal cells suggesting that the dense fibrotic stromal tissue in these types of tumors does not constitute an inert barrier to invasion, but rather is an active contributor to tumor growth and invasion. That was consistent with the study of Yan et al ${ }^{[6]}$ who also reported cathepsin $\mathrm{K}$ expression in stromal cells of all Tables legends
SCC cases which was significantly higher than the other studied epidermal tumors $(\mathrm{P}<$ 0.001 ).

A significant correlation between the epithelial and the stromal scores of cathepsin $\mathrm{K}$ was detected in all the four studied tumors $(p=0.01)$. The highest correlation coefficients were reported in the BCC and SCC groups. The expression levels of cathepsin K in SCC cases significantly correlated with the tumor grade $(\mathrm{p}=0.01)$. Hassan et al ${ }^{[20]}$ who studied the expression of another member of the cathepsin family (cathepsin D) in epidermal tumors including SCC demonstrated significant positive correlation between the expression levels and the advancement in the histological grade of SCC. This provides strong evidence that cathepsins can be used a useful predictors for invasiveness.

Regarding dermoscopic findings, there was statistically significant correlation between the positivity of cathepsin $\mathrm{K}$ and the finding of dermoscopic hemorrhage in SCC lesions. According to lallas et al ${ }^{[21]}$, the extensive presence of vessels and dermoscopic hemorrhage were significantly associated with poor SCC differentiation, while kertain structures were a potent predictor of well or moderately differentiated tumors. This could serve as an explanation of the positive correlation between the dermoscopic hemorrhage in SCC and the higher expression of proteases.

To summarize, cathepsin $\mathrm{K}$ has a role in the growth and expansion of epidermal tumors not only in malignant tumors but also in benign ones. The peritumoral stroma is an active contributor in tumor invasiveness. The increased activity of cathepsin K can be used as a predictor of increased risk for invasion. Cathepsin $\mathrm{K}$ inhibitors that have been currently investigated can be a promising therapeutic line for the treatment of cutaneous tumors.

No conflict of interest. 
Table 1. Demographic, clinical and histological data of the studied groups.

\begin{tabular}{|c|c|c|c|c|c|}
\hline & SK & AK & BCC & SCC & Normal \\
\hline \multicolumn{6}{|l|}{ Age } \\
\hline Range & $48-72$ & $41-62$ & $51-63$ & $35-65$ & $34-65$ \\
\hline Mean \pm SD & $56.56 \pm 7.10$ & $54.67 \pm 6.50$ & $54.78 \pm 3.80$ & $46.33 \pm 11.25$ & $53.11 \pm 10.32$ \\
\hline \multicolumn{6}{|l|}{ Sex $[\mathrm{N}(\%)]$} \\
\hline Male & $7(77.8)$ & $4(44.4)$ & $6(66.7)$ & $1(11.1)$ & $4(44.4)$ \\
\hline Female & $2(22.2)$ & $5(55.6)$ & $3(33.3)$ & $8(88.9)$ & $5(55.6)$ \\
\hline \multicolumn{6}{|l|}{ Site [N $(\%)]$} \\
\hline Head \&neck & $7(77.8)$ & $9(100)$ & $7(77.8)$ & $9(100)$ & $9(100)$ \\
\hline Acral & $1(11.1)$ & & $1(11.1)$ & & \\
\hline Trunk & $1(11.1)$ & & $1(11.1)$ & & \\
\hline $\begin{array}{l}\text { Grade/ type } \\
{[\mathrm{N}(\%)]}\end{array}$ & $\begin{array}{c}\text { Acanthotic } \\
3(33.3) \\
\text { Hyperkeratotic } \\
3(3.33) \\
\text { Reticulated } \\
3(33.3)\end{array}$ & $\begin{array}{c}\text { Atrophic } \\
5(55.5) \\
\text { Hypertrophic } \\
2(22.2) \\
\text { Bowenoid } \\
1(11.1) \\
\text { Pigmented } \\
1(11.1) \\
\end{array}$ & $\begin{array}{c}\text { Nodular } \\
4(44.4) \\
\text { Superficial } \\
2(22.2) \\
\text { Pigmented } \\
1(11.1) \\
\text { Adenoid } \\
2(22.2) \\
\end{array}$ & $\begin{array}{l}\text { Grade } 1 \\
4(44.4) \\
\text { Grade } 2 \\
2(22.2) \\
\text { Grade } 3 \\
3(33.3)\end{array}$ & \\
\hline Total [N (\%)] & $9(100)$ & $9(100)$ & $9(100)$ & $9(100)$ & $9(100)$ \\
\hline
\end{tabular}

$\mathrm{N}=$ number

$\mathrm{SD}=$ standard deviation

Table2. dermoscopic findings in the studied epidermal tumors.

\begin{tabular}{|l|l|l|l|l|l|}
\hline SK & & & AK & & \\
\hline Comedo-like openings & 6 & $66.6 \%$ & Pseudonetwork & 9 & $100 \%$ \\
\hline Milia like cysts & 5 & $55.5 \%$ & Annular granular pattern & 5 & $55.5 \%$ \\
\hline Fissures and ridges & 4 & $44.4 \%$ & Rhomboidal structures & 3 & $33.3 \%$ \\
\hline Moth eaten border & 1 & $11.1 \%$ & & & \\
\hline Cerebriform pattern & 3 & $33.3 \%$ & & & \\
\hline Finger prints & 1 & $11.1 \%$ & & & \\
\hline Honeycomb pattern & 1 & $11.1 \%$ & & & \\
\hline Pseudonetwork & 1 & $11.1 \%$ & & & \\
\hline Brown globules & 1 & $11.1 \%$ & & & \\
\hline BCC & & & SCC & & \\
\hline Arborizing vessles & 4 & $44.4 \%$ & Vascular structures & 4 & $44.4 \%$ \\
\hline Telengectasia & 4 & $44.4 \%$ & White circles & 4 & $44.4 \%$ \\
\hline Blue ovoid nests & 6 & $66.6 \%$ & White structure less areas & 4 & $44.4 \%$ \\
\hline Blue peppering & 4 & $44.4 \%$ & Hemorrhage & 5 & $55.5 \%$ \\
\hline Spoke wheel structures & 1 & $11.1 \%$ & Scales & 9 & $100 \%$ \\
\hline Maple leaf like areas & 5 & $55.5 \%$ & & & \\
\hline Central hemorrhage & 5 & $55.5 \%$ & & & \\
\hline White shiny structures & 5 & $55.5 \%$ & & & \\
\hline Scales & 5 & $55.5 \%$ & & & \\
\hline
\end{tabular}


Table 3. Comparison between the case and control groups regarding the epithelial and stromal scores.

\begin{tabular}{|lcc|c|c|c|c|c|c|}
\hline & SK & AK & BCC & SCC & Total & control & P \\
\hline $\begin{array}{l}\text { Cathepsin K (E) } \\
\text { Range }\end{array}$ & $0-1$ & $0-1$ & $1-3$ & $1-3$ & $0-3$ & $0-1$ & $<0.001$ \\
Mean \pm SD & $0.067 \pm 0.5$ & $0.89 \pm 0.33$ & $2 \pm 0.86$ & $1.78 \pm 0.97$ & $1.33 \pm 0.89$ & $0.22 \pm 0.44$ & HS \\
\hline $\begin{array}{l}\text { Cathepsin K (S) } \\
\text { Range }\end{array}$ & $0-2$ & $0-1$ & $0-3$ & $1-3$ & $0-3$ & $0-1$ & $<0.001$ \\
Mean \pm SD & $1.22 \pm 0.83$ & $0.89 \pm 0.33$ & $2 \pm 1.00$ & $2.11 \pm 0.78$ & $1.56 \pm 0.90$ & $0.22 \pm 0.44$ & HS \\
\end{tabular}

$\mathrm{E}=$ epithelial score

$\mathrm{S}=$ stromal score

$\mathrm{HS}=$ highly significant

Table 4. Comparison between the benign and the invasive tumors groups regarding the epithelial and stromal scores.

\begin{tabular}{|c|c|c|c|}
\hline & $\begin{array}{l}\text { Benign tumors } \\
(\mathrm{SK}, \mathrm{AK})\end{array}$ & $\begin{array}{c}\text { Invasive tumors } \\
\text { (BCC, SCC) }\end{array}$ & $\mathbf{P}$ \\
\hline $\begin{array}{l}\text { Epithelial score } \\
\text { Range } \\
\text { Mean } \pm \text { SD }\end{array}$ & $\begin{array}{c}0-1 \\
0.78 \pm 0.42\end{array}$ & $\begin{array}{c}1-3 \\
1.89 \pm 0.90\end{array}$ & $<0.001 \mathrm{HS}$ \\
\hline $\begin{array}{l}\text { Stromal score } \\
\text { Range } \\
\text { Mean } \pm \text { SD }\end{array}$ & $\begin{array}{c}0-2 \\
1.06 \pm 0.639\end{array}$ & $\begin{array}{c}0-3 \\
2.06 \pm 0.87\end{array}$ & $<0.001 \mathrm{HS}$ \\
\hline
\end{tabular}

HS= highly significant

Figures legends 

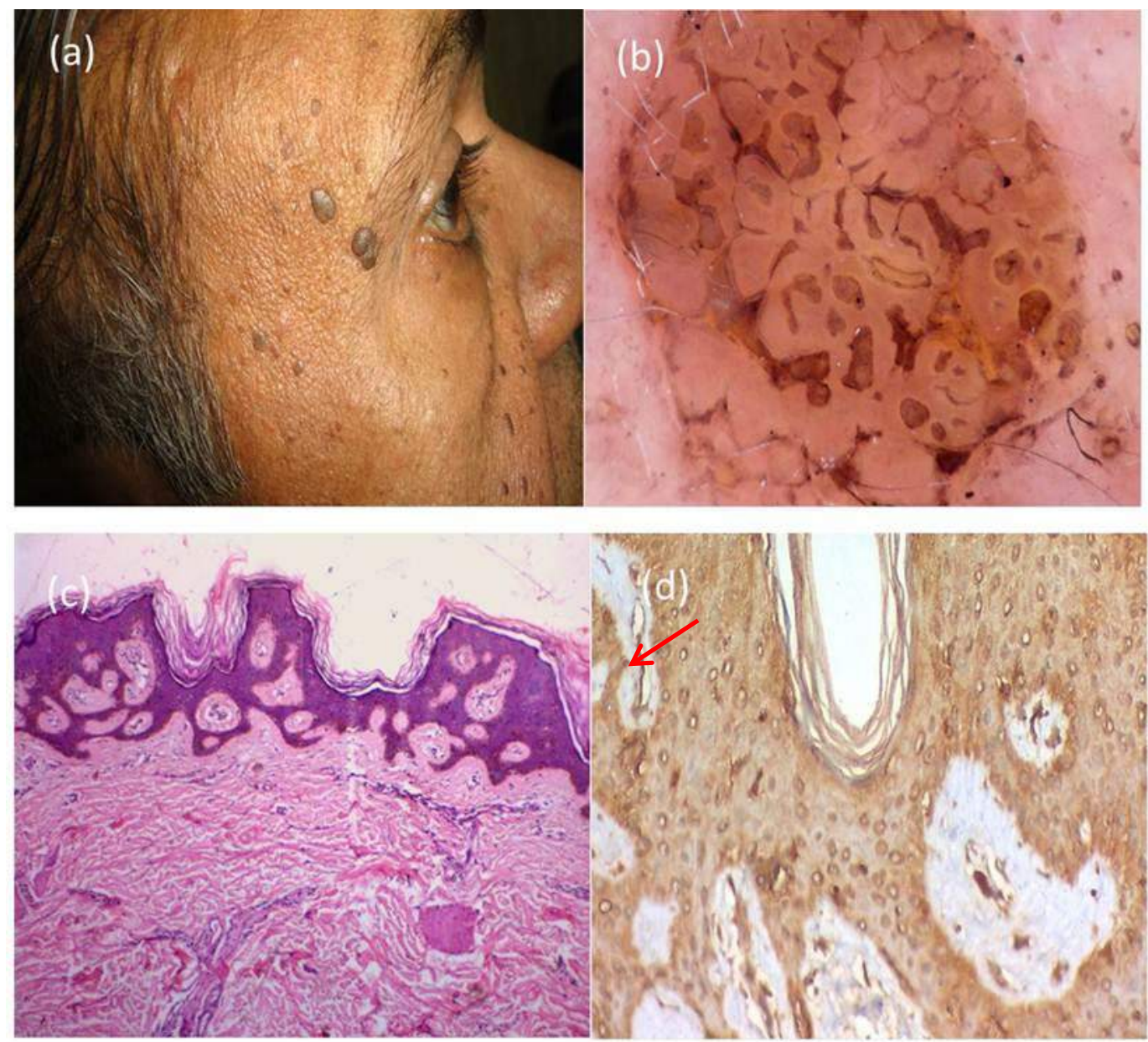

Figure 1. A male patient with SK (a), dermoscopy shows cerebriform pattern, comedo like openings, fissures and ridges (b), histological examination shows adenoid variant (H\&E x200) (c), mild positivity for cathepsin $\mathrm{K}$ (red arrow) (epithelial score +1 ) by immunohistochemical examination (x 400) (d).

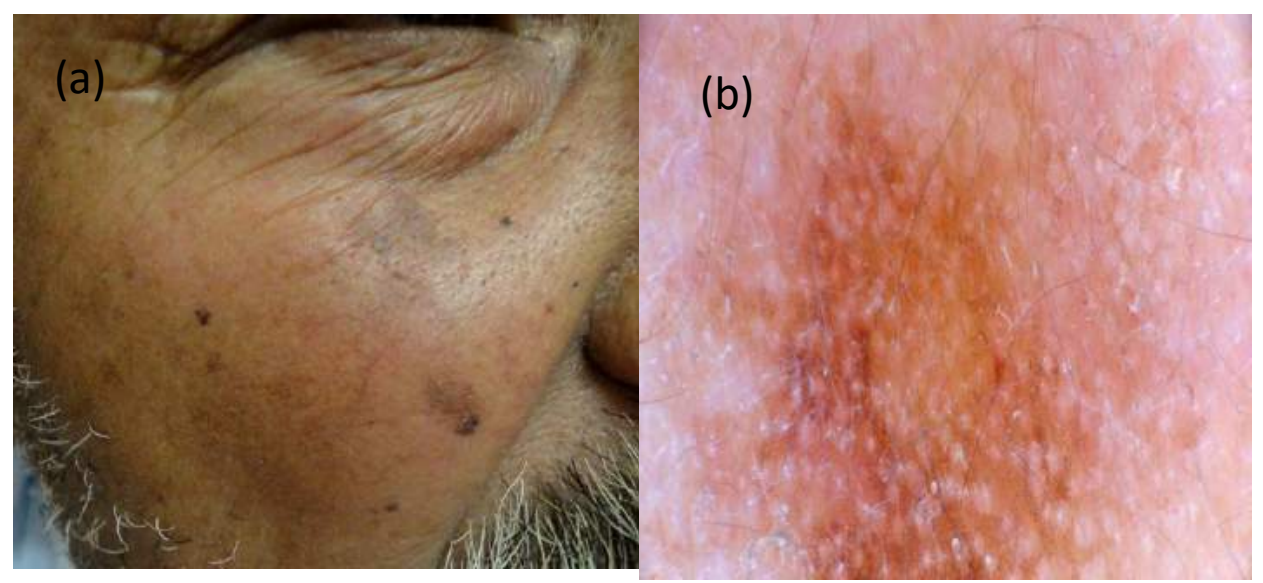




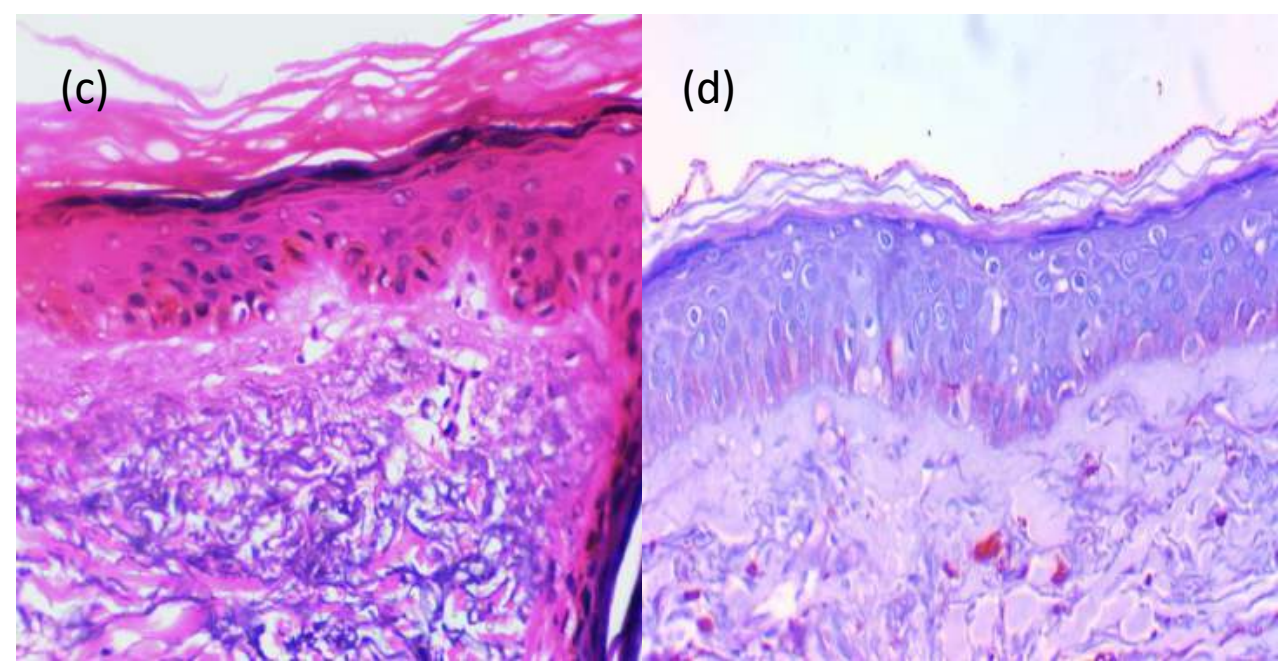

Figure 2. a male patient with an actinic keratosis on the face (a), dermatoscopic examination shows pigmented pseudonetwork, annular granular pattern and rhomboidal structures (b), histological examination of the lesion shows atrophic variant (H\&E x 200) (c) and immunohistochemical examination shows absent staining for cathepsin $\mathrm{K}$ (epithelial score 0 and stromal score 0 , x 200 magnification) (d).

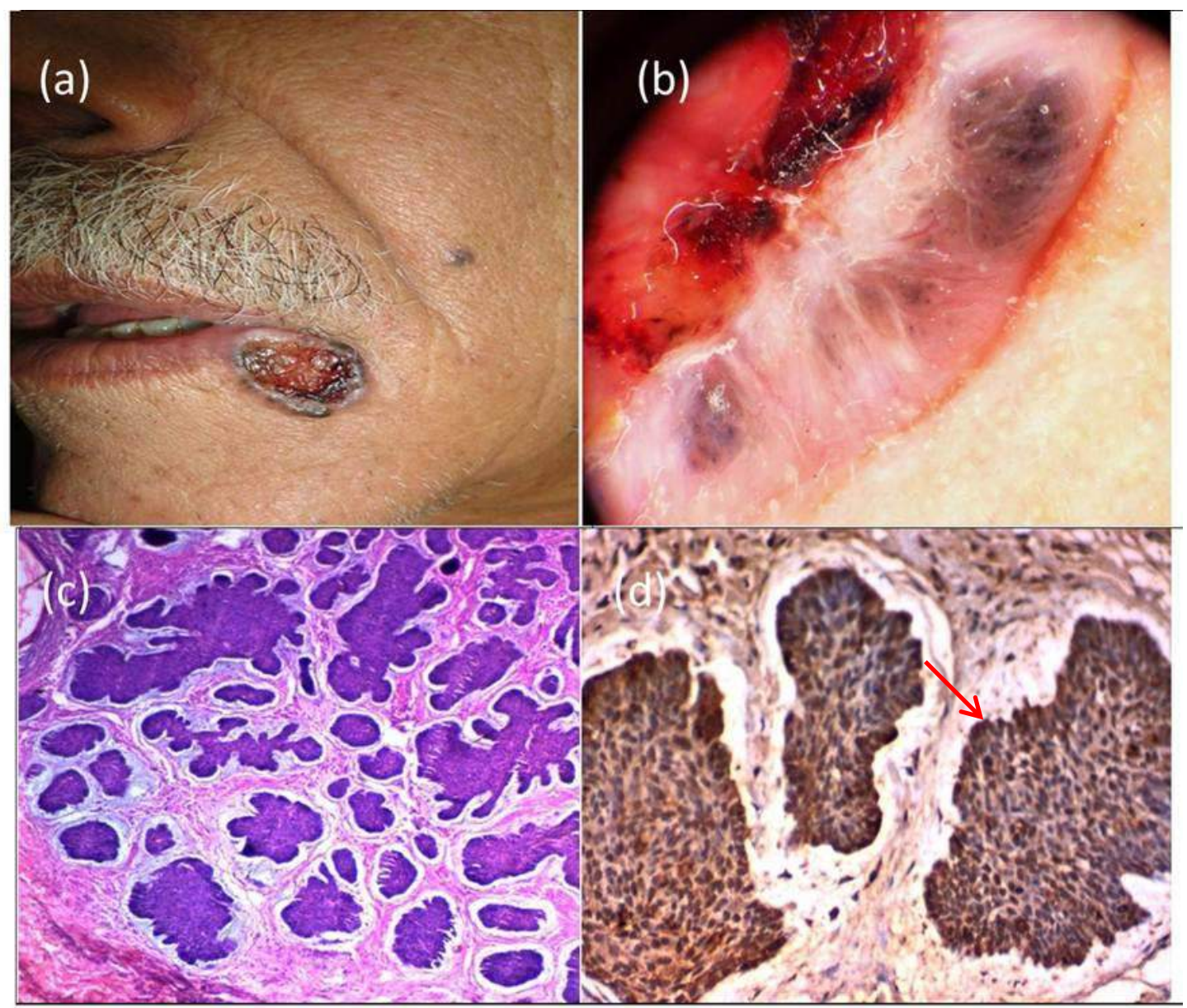

Figure 3. A male patient with BCC (a), dermoscopy shows central hemorrhage, bluish /brown leaf like structures, dots, serpentine vessels and white shiny structures (b), histological examination shows nodular and micronodular BCC variants by (H\&E x 200 magnification) (c), strong positivity 
for cathepsin $\mathrm{K}$ (red arrow) (epithelial score +3 , stromal score +3 ) by immunohistochemical examination for cathepsin K (x 400) (d).

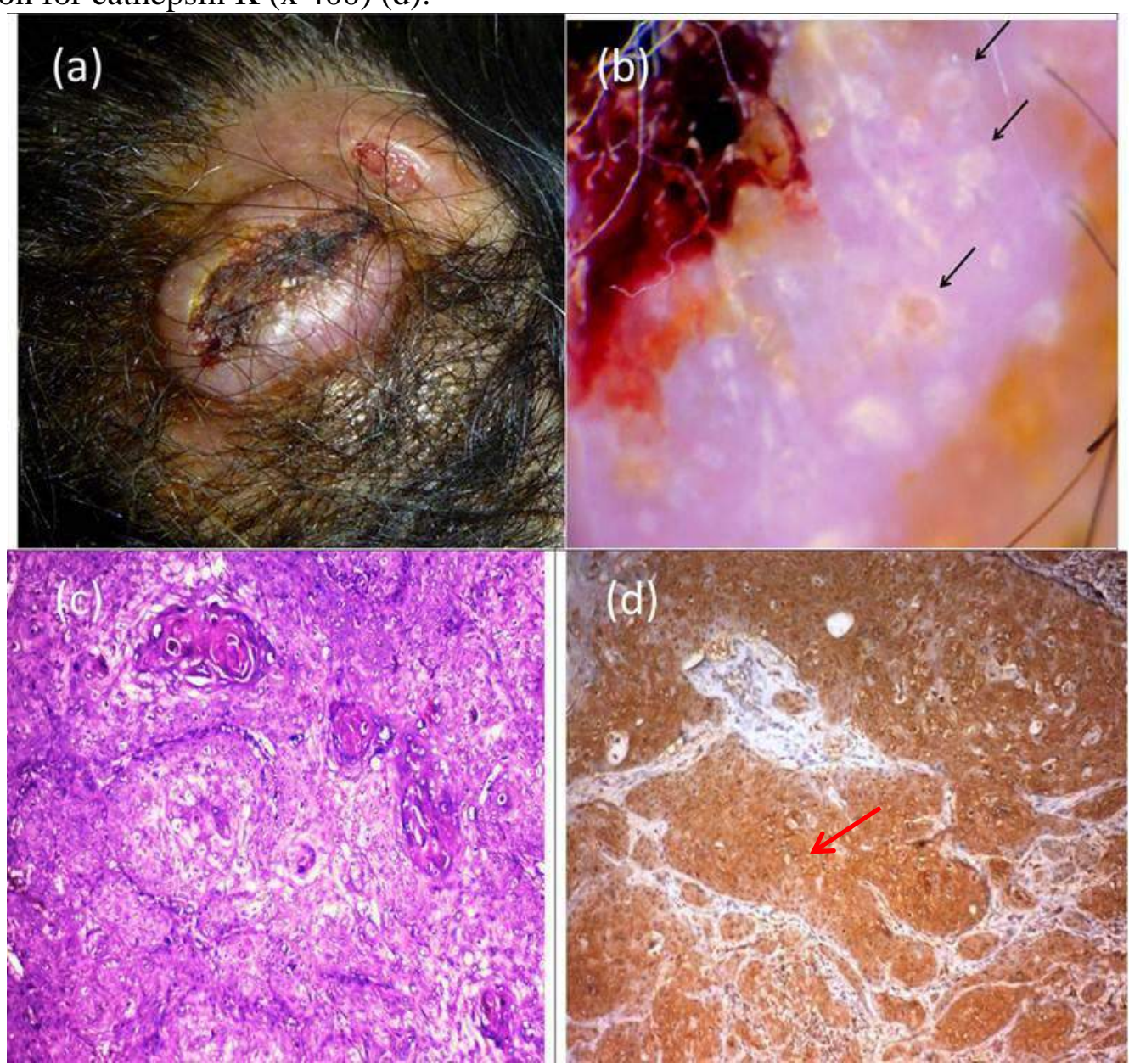

Figure 4. A female patient with SCC on the scalp (a), dermoscopy shows hemorrhage and white circles (black arrows) (b), SCC grade 3 by H\&E examination (x 200 magnification) (c), moderate positivity for cathepsin $\mathrm{K}$ (red arrow) (epithelial score +2 , stromal score +2 ) by immunohistochemical examination for cathepsin K (x 200 magnification) (d).

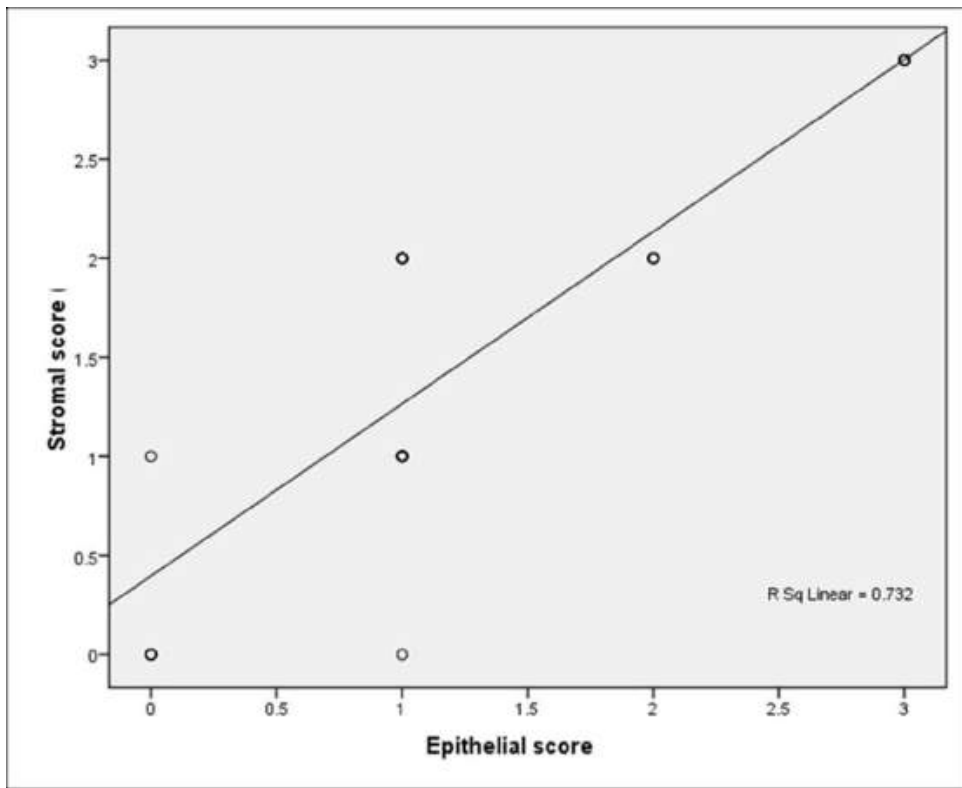

Figure 5. Correlation between the epithelial and the stromal scores of the case groups. 


\section{REFERENCES}

1. Bissell MJ and Hines WC. Why don't we get more cancer? A proposed role of the microenvironment in restraining cancer progression. Nat Med 2011; 17(3):320-9.

2. Rawlings ND, Waller M, Barrett AJ and Bateman A. MEROPS: the database of proteolytic enzymes, their substrates and inhibitors. Nucleic Acids Res 2014; 42: 503509.

3. Turk V, Stoka V, Vasiljeva O, Renko M, Sun T, Turk B, Turk D. Cysteine cathepsins: from structure, function and regulation to new frontiers. Biochim Biophys Acta 2012; 1824(1):68-88.

4. Stoka V, Turk V and Turk B. Lysosomal cathepsins and their regulation in aging and neurodegeneration. Ageing Res Rev 2016; 32: 22-37.

5. Quintanilla-Dieck M, Codriansky K, Keady M Bhawan J, Rünger TM. Cathepsin K in Melanoma Invasion. Journal of Investigative Dermatology 2008; 128(9): 2281-2288.

6. Yan $\mathbf{X}$, Takahara $\mathrm{M}$, Xie L, Oda $\mathbf{Y}$, Nakahara T, Uchi $\mathbf{H}$, et al. Stromal expression of cathepsin $\mathrm{K}$ in squamous cell Carcinoma. JEADV 2011; 25, 362-365.

7. Ishida M, Kojima $F$ and Okabe $H$. Cathepsin $\mathrm{K}$ expression in basal cell carcinoma. J Eur Acad Dermatol Venereol 2013; 27(1): 128-30.

8. Gill D, Dorevitch A and Marks R. The prevalence of seborrheic keratoses in people aged 15 to 30 years: is the term senile keratosis redundant? Arch Dermatol 2000; 136: 759-762.

9. Feldman $\mathbf{S}$ and Fleischer A. Progression of actinic keratosis to squamous cell carcinoma revisited: clinical and treatment implications. Cutis 2011; 87(4): 201-207.

10. Rubin A, Chen $\mathbf{E}$ and Ratner D. Basal-cell carcinoma. N Engl J Med 2005; 353(21):2262-9.

11. Shulstad R and Proper S. Squamous Cell Carcinoma: A Review of Etiology, Pathogenesis, Treatment, and Variants. Journal of the Dermatology Nurses' Association 2010; 2: 12-16.

12. Martorell-Calatayud A, Sanmartín Jimenez O, Cruz Mojarrieta J and Guillén
Barona C. Cutaneous squamous cell carcinoma: defining the high-risk variant. Actas Dermosifiliogr 2013; 104(5): 367-79.

13. Hsu SM, Raine L, Fanger H (1981): Use of avidin-biotin-peroxidase complex $(\mathrm{ABC})$ in immunoperoxidase techniques: a comparison between $\mathrm{ABC}$ and unlabeled antibody (PAP) procedures. J Histochem Cytochem; 29(4): $577-80$.

14. Koontongkaew S. The Tumor Microenvironment Contribution to Development, Growth, Invasion and Metastasis of Head and Neck Squamous Cell Carcinomas. J Cancer 2013; 4(1):66-83.

15. Fischer A. Mechanism of the proteolytic activity of malignant tissue cells. Nature 1946; 157: 442.

16. Chianeh YR and Prabhu K. Biochemical markers in saliva of patients with oral squamous cell carcinoma. Asian Pac J Trop Dis 2014; 4(1): 33-S40.

17. Rao Q, Wang Y, Xia QY, Shi SS, Shen $\mathbf{Q}$, Tu $\mathbf{P}$ et al. Cathepsin $\mathrm{K}$ in the immunohistochemical diagnosis of melanocytic lesions. Int J Clin Exp Pathol 2014; 7(3): 1132-1139.

18. Frohlich E, Mohrle $\mathbf{M}$ and Klessen $\mathbf{C}$. Cathepsins in basal cell carcinomas: activity, immunoreactivity and mRNA staining of cathepsins B, D, H and L. Arch Dermatol Res 2004; 295:411-421.

19. Tsuboi R1, Yamaguchi T, Kurita Y, Nakao H, Ogawa H, Ishihara $K$. Comparison of proteinase activities in squamous cell carcinoma, basal cell epithelioma and seborrheic keratosis. J Invest Dermatol 1988; 90:869-872.

20. Hassan A, El-Ashmawy A, Shareef M and AbdElazeem M. immunohistochemical expression of cathepsin D and matrix metalloproteinase-9 in common epidermal tumors. Journal of the Egyptian Women's Dermatologic Society 2014, 11:87-94.

21. Lallas A, Pyne J, Kyrgidis A, Andreani S, Argenziano G, Cavaller A et al. The clinical and dermoscopic features of invasive cutaneous squamous cell carcinoma depend on the histopathological grade of differentiation. $\mathrm{Br} \quad \mathrm{J}$ Dermatol 2015; 172(5):1308-15. 